DOI: $10.7256 / 2073-8560.2013 .5 .9414$

\title{
ВОКТРИНА
}

\section{ПРОЦЕСС ЯДЕРНОГО РАЗОРУЖЕНИЯ И РАЗРУШЕНИЕ ХАРТЛЕНДА}

Аннотация: в статье рассмотрены проблемы вызванные процессом ядерного разоружения России и США. Целью исследования - определить характер влияния российско-американских отношений в сфере разоружения на изменение традиционных геополитических представлений. Рассмотрены изменения в понимании роли ядерного оружия в период холодной войны. Проанализированы характерные особенности влияния американских военных доктрин и стратегий на внешнюю политику Соединенных Штатов и предпринятых действий США в отношении СССР и России. Выявлена и обоснована необходимость симметричного ответа Российской Федерации на внешнеполитические угрозы, которые провоцирует процесс ядерного разоружения. На основе проведенного исследования автором выделяется особенность трансформации хартленда в условиях наращивания и снижения ядерного потенииала. Классическая геополитика деформируется с появлением и развитием ядерного вооружения. Традиционные геополитические правила игры на «мировой шахматной доске» получают большое количество исключений, что усложняет возможность объективной оченки и создает высокий потенцииал для точек бифуркации, где невозможно точно спрогнозировать направление дальнейшего развития. Геополитическая парадигма в международных отношениях, таким образом, теряет свое значение, уступая более объективным парадигмам, в частности реализму и либерализму. Одним из следствий разоружения является возврат к исходным геополитическим позициям, где возможны военные действия без нанесения упреждающего удара, способного уничтожить противника

Ключевые слова: ядерное разоружение, «хартленд», внешняя политика США, геополитическая парадигма, военные доктрины США, стратегия США, гонка вооружений, холодная война, разрушение Советского Союза, СНВ.

Review: the article is devoted to the problems caused by the nuclear disarmament of the Russian Federation and the USA. The goal of the study is to establish the character of influence of the Russian-American relations in the sphere of disarmament on the changes in traditional geopolitical views. The author analyzes changes in perception of nuclear weapons in the Cold War period, as well as specific features of influence of the American military doctrines and strategies on the foreign policy of the USA, and the acts of the USA towards the USSR and Russia. The author provides 
the fundamentals for the necessity of symmetrical response of the Russian Federation towards the foreign political threats provoked by the process of nuclear disarmament. Based upon the studies the author establishes the specific features of the Heartland transformation in the conditions of growing and diminishing nuclear disarmament. The classical geopolitics is being deformed by appearance and development of nuclear weapons. Traditional geopolitical rules for the "global chess desk" are complicated with a large number of exceptions, complicating the possibilities for the objective evaluations and forming high potential for the bifurcation points, where it is impossible to forecast the further development vector. Therefore, the geopolitical paradigm in the international relations loses its value, giving way to more objective paradigms, such as realism and liberalism. One of the consequences of disarmament is return to the primary geopolitical positions, where military actions are possible without preventive blows, capable of destroying the opponent.

Keywords: nuclear disarmament, Heartland, foreign policy, the USA, geopolitical paradigm, military doctrines of the USA, strategy of the USA, armaments race, destruction of the Soviet Union, strategic nuclear forces.

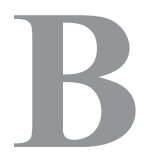

1940 г. в Академии наук СССР была создана комиссия по проблеме урана, объединившая работу ряда научноисследовательских институтов, в области физики атомного ядра. После начала Великой Отечественное войны практически все работы в области ядерной физики были на время прекращены. Только с 1942 г. была принята программа изучения возможности создания ядерного оружия, реализация которой была связана с появившимися у советского руководства развединформацией от том, что Великобритания и США уже ведут работу в этом направлении. Позже всю операции разведки СССР в по ядерному оружию назовут «Манхетенский проект». В апреле 1943 г. была образована Лаборатория № 2, ознаменовавшая начало советского атомного проекта, а уже 29 августа 1949 г. на испытательном полигоне в Семипалатинске было проведено испытание первого советского ядерного устройства. К концу 50-х годов СССР обладал значительным арсеналом ядерных боезарядов и средств доставки, позволявшие использовать ядерное оружие в пределах театров боевых действий. Тогда же основные усилия Советского Союза были направлены на создание средств межконтинентальной доставки зарядов, способных достигать территории США. Отражение угрозы ядерного нападения со стороны США определило необходимость создания межконтинентальных средств доставки ядерного оружия. Удачное испытание межконтинентальной баллистической ракеты P-7 (SS-6) и её использование осенью 1957 г. для запусков первых искусственных спутников Земли продемонстрировали лидерство Советского Союза в области создания баллистических ракет. Подобная революция в вооружении привела к пересмотру основных геополитических концепций. Классическая основа геополитики заложенная X. Маккиндером, А. Мэхеном и Н. Спайкманом требовала пересмотра в контексте появления ядерного оружия и межконтинентальных средств доставки, которые существенно уменьшали фактор «морской силы» («sea power» по А. Мэхену) и ослабляли формулу Н. Спайкмана «кто владеет «римлендом», тот владеет «хартлендом», а значит и всем миром». Результатом подобных изменений явилась гонка вооружений.

В 1982 г. СССР первым объявил об отказе от применения ядерного оружия. В то время в Институте прикладной ма- 
тематики Академии Наук СССР родилась идея ограничения стратегических вооружений и систем противоракетной обороны - одна из наиболее глубоких и важных идей двадцатого века. Эта идея, выдвинутая М. В. Келдышем, С. П. Курдюмовым ${ }^{1}$, Д.Ф. Устиновым и А.А. Громыко на десятилетие опередила повестку дня для диалога сверхдержав. Она позволяла экономить гигантские ресурсы, повысить уровень доверия в мировом сообществе и, в конечном итоге, обеспечила много лет мирного сосуществования без кризисов, выходящих на военно-стратегический уровень. Но в то же время С.П. Курдюмов одним из первых доказал путем анализа и моделирования, идею, того что ядерное оружие вместо гаранта стабильности может превратиться в свою противоположность. Идея, что наш мир нелинеен, способен к противоречивому поведению, уже тогда представлялась очевидной, но её применение к конкретным реалиям воспринималось неоднозначно. Паритет стратегических вооружений, обеспечивший полвека мира, исходил из возможности каждой из сторон нанести другой неприемлемый ущерб на любой стадии конфликта. Это и уберегает каждую из сторон от соблазна такой конфликт начать. Однако предположим, что в процессе сокращения вооружений пусть даже симметричном, взаимном и контролируемом, достигнут и некоторый критический порог, при котором каждая из сторон может нанести неприемлемый ущерб в первом обезоруживающем ударе, но не может сделать это, нанося ответный удар. И тогда

\footnotetext{
${ }^{1}$ Курдюмов С.П. (1928-2004) — советский и российский ученый, специалист во области моделирования, нелинейного анализа и синергетики. Членкорреспондент советской АН СССР. Считается основателем синергетического движения в России.
}

появляется соблазн нанести удар первым ${ }^{2}$. Предложения о сокращении стратегических вооружений и средств средней дальности были выдвинуты Советским Союзом в ходе советско-американской встречи в верхах в Рейкьявике, состоявшейся в октябре 1986 г. За период с 1990 до 2002 г. общее число носителей элементов российской ядерной триады (наземное, морское и авиационное базирование) сократилось с 2500 до 1505 единиц, а ядерных боезарядов - с 10271 до 5518 единиц ${ }^{3}$.

8 апреля 2010 г. в Праге Д. Медведев и Б. Обама подписали новый Договор между Российской Федерацией и Соединенными Штатами Америки о мерах по дальнейшему сокращению и ограничению стратегических ядерных наступательных вооружений, что приближает нас к возможному сценарию предложенному С. П. Курдюмовым.

Между тем, в средствах массовой информации нередки высказывания первых лиц иностранных государств о разделе России ${ }^{45}$. Очевидно, что за их выступлениями скрываются тщательно проработанные соответствующими генштабами геополитические проекты, направленные против России, представляющие собой четкий алгоритм, т.е. последовательное достижение каждого этапа плана за некоторый промежуток времени, учитывающие современные реалии

\footnotetext{
${ }^{2}$ Агеев А.И. Курдюмов В. С., Малинецский Г.Г. Проек тирование будущего. Кризис и идеи С.П. Курдюмова // Экономические стратегии. 2009. № 4.

${ }^{3}$ Официальный сайт Центра по изучению проблем разоружения, энергетики и экологии МФТИ http;//www. armscontrol.ru/start/rus/

${ }^{4}$ Голос Америки. Среда, 22 Февраль 2012. http:// voanews.com/russian/grigoryev/tag/олбрайт/

${ }^{5}$ Хиллари Клинтон: Мы не дадим России объединиться с соседями 07.12.2012. http://www.pravda.ru/news/world/07-122012/1137689-hillari_doesnt_like_it-0/
} 
в отношении сокращения стратегического ядерного вооружения. В отличие от заранее спланированных ходов, совершаемых нашими оппонентами на «мировой шахматной доске», Россия вынуждена давать на них ситуативные ответы. Понимание механизма работы внешнеполитических зарубежных концепций способствует формированию долгосрочных контрмер на внешние вызовы.

Известно, что теория и практика внешней политики США основывается на «трех китах»: идее американского жизненного пространства, заимствованной из работ классика Мюнхенской школы геополитики К. Хаусхоффера, теории подвижных границ и идеологии так называемой «идеи фронтира», о миссианской роли США в современном мире. В качестве механизма ее реализации используются принципы политики «открытых дверей», доктрины Монро и стратегии «кольцо Анаконды». В планетарном масштабе для создания Pax America антлантисты используют идеи концепции Х. Маккиндера, адаптируя её к современным реалиям.

На глобальном уровне концепция «хартленда» представляет собой планетарную модель расположения глобальных сил, при этом наиболее тривиальным считается взгляд о противостоянии стран суши и моря. Ойкумена «хартленда» - это ареал от Восточной Европы до побережий Тихого океана, от Ирано-Тибетской области до побережий Северно-Ледовитого Океана. Однако, под влиянием сложившейся идеологической конъюнктуры, его контуры эволюционировали до государственных границ СССР, а затем и Российской Федерации.

Исходя из логики максимы Х. Маккиндера, США должны были установить свое влияние в Европе, чтобы потом контролировать CССР. Поэтому после окончания войны под руководством А. Даллеса вступил в силу одноименный план по разрушению СССР, ко- торый представлял собой четкий алгоритм. В теории информации под ним понимают строгую последовательность действий, направленных на достижение поставленных задач, обладающих следующими свойствами: 1) дискретность - решение задачи через строго последовательное выполнение шагов; 2) детерминированность - в каждый момент времени, следующий шаг работы однозначно определяется состоянием системы; 3) результативность - достижение цели за конечное число шагов; 4) массовость - применимость к разным наборам исходных данных.

Провозглашенные внешнеполитические доктрины США на протяжении 50 лет по нашему мнению являются этапами такого алгоритма. Первым шагом стала доктрина Трумэна: сдерживание СССР, создание военных баз вокруг Евразии, формирование демократического оплота в лице Европы (план Маршалла), в результате образовался военно-политический блок НАТО. Следующим была доктрина Эйзенхауэра, которая основывалась на теории «массированного возмездия», т. е. увеличение количества стратегического оружия и его носителей, втягивание СССР в гонку вооружений. Она предписывала возможность нанесения внезапного ядерного удара по СССР и КНР с последующей оккупацией их территорий. Третьим стал принятый конгрессом США закон «о порабощенных нациях», в котором сказано, что, во-первых, советский коммунистический режим проявил агрессию к народам и в частности лишил независимости Польшу, Украину, Казакию, Кавказ, Грузию, Азербайджан, Вьетнам, Албанию, Эстонию и т.д.; во-вторых, необходимо проводить комплекс мероприятий до тех пор, пока этносы не станут свободными. Четвертым доктрина Картера, которой было объявлено, что Персидский залив является регионом национальных интересов США. В соответ- 
ствии с этим, любые попытки получить контроль над ним, будут расцениваться как прямая угроза Америке. Пятылм - доктрина Джонсона: США присваивают право, невзирая на суверенитет, совершать силовое вмешательство во внутренние дела государств Запада и азиатско-тихоокеанского региона для защиты интересов своих граждан. Шестыл - доктрина Рейгана, ратовавшего за свержение просоветских, прокоммунистических и антиамериканских режимов в странах третьего мира, приведшая к новому витку гонки вооружений, который СССР уже не смог потянуть. Седьмым - доктрина Пауэлла, в которой регламентировалось применение американских вооруженных сил при условии наличия угрозы жизненно-важным интересам США или их союзникам, при этом поставленная цель должна быть достигнута в любом случае, а также военные операции должны быть поддержаны народом и конгрессом до их начала ${ }^{1}$.

Таким образом, «хартленд» СССР был разрушен за «семь шагов», при этом каждый шаг был основан на анализе внешнеполитических ситуаций в мире. В геополитическом пространстве алгоритм реализовывался по трем направлениям. Первое - глобальный охват Евразии - установление своего влияния в Европе, Японии, странах Персидского залива, с последующим правом вторжения в любую страну, если есть угроза а) национальным интересам США и их союзникам; б) собственным гражданам. Второе - региональное развитие сепаратизма - использование идеи национальной идентичности и религиозной принадлежности для провозглашения суверенных государств. Благодаря чему проявилось влияние США в странах

\footnotetext{
${ }^{1}$ Captive national week // Bush G. W. / сайт: архива Белого Дома. http://georgewbush-whitehouse.archives. gov/news/releases/2008/07/20080718-3.html
}

Варшавского договора, а также образовалось 15 новых республик на политической карте мира. Третье - изучение военной географии CССР, т.е. определение местонахождения стратегических объектов, военно-промышленной инфраструктуры и т.д.

Алгоритм работает тогда, когда есть дальнейшая возможность его применения к решению подобных задач, а этому как нельзя лучше способствует фактор разоружения и возвращения мира в военном смысое в доядерную эру, когда базовые понятия геополитики играли первоочередное значение во внешнеполитическом планировании.

Соответственно, в качестве исследуемого полигона на мезоуровне выступает пространство Российской Федерации. А сформировавшаяся пространственная мозаичность из 15 республик после развала СССР является стыковым образованием между макро- и мезоуровнем ${ }^{2}$.

Дестабилизационные процессы, возникшие после распада СССР, прямо или косвенно подтвердили начало реализации замысла западных стратегов. Прежде всего, это выразилось в сепаратистских устремлениях регионов (Ичкерия, Татарстан, Башкирия, Якутия и т.д.), приватизации частными лицами крупнейших предприятий страны, следствием чего стал неконтролируемый вывоз капитала - существенной части российского ВВП. Ухудшилась социально-экономическая ситуация, образовалась пропасть между богатыми и бедными слоями населения, появились маргинальные общности, началась «утечка умов» и т. д. (Есть основания предполагать, что за десятилетний период кризиса стратеги США рассчитывали на «самостоятельный» распад России). Как следствие - увеличился риск попадания оружия массового пораже-

\footnotetext{
${ }^{2}$ A geostrategy for Eurasia. // Foreign Affairs / September/October 1997, p. 50-64
} 
ния на теневой рынок, появление терроризма с угрозой применения ядерного оружия. Однако развитие демократии и рыночной экономики, наличие достаточного ядерного арсенала дало возможность РФ сохранить суверенитет.

Однако идея разделения нашей страны не покинула умы стратегов. Известный специалист по внешней политике 3б. Бжезинский (США), вопреки здравому смыслу, считает, что для России проблема потери территории не является приоритетной и не должна волновать ее правительство, а ключевой, по его мнению, является поддержка экономических связей через создание конфедеративного государства из европейской России, Сибирской и Дальневосточной республик ${ }^{1}$. Другими словами он предлагал создать союз между тремя отдельными государствами. Образование федеральных округов (2000 г.), «скрепивших» геополитическое пространство России, по сути явилось ответным ходом на тактические маневры атлантических стратегов.

После событий 11 сентября 2001 г. у многих деятелей США произошла трансформация образа врага — от «коммунистической империи зла» к «террористической». Первым шагом стала доктрина Буша: свержение режимов в странах, которые представляют потенциальную или предполагаемую угрозу для безопасности США, ее союзниками и интересам, даже если угроза не является непосредственной.

Фактически она не только не отличалась по смыслу от доктрин Джонсона, Картера, Рейгана, Пауэлла, но и явилась их синтезом. Отметим, что после окончания холодной войны военная инфраструктура, расположенная по всему миру, осталась

\footnotetext{
${ }^{1}$ A geostrategy for Eurasia. // Foreign Affairs /
} September/October 1997, p. 50-64 под влиянием США, а НАТО расширилась до границ России. В итоге произошло вторжение американцев в Афганистан и в Ирак (2001 и 2002 гг. соответственно). Начались «цветные» революции на постсоветском пространстве, «газовые войны» между Россией и Украиной. Вторым шагом стоит считать провозглашенную в июле 2008 г. Дж. Бушем «неделю порабощенных наций». Результатом этого «хода» в августе происходит конфликт между Грузией и Южной Осетией, а осенью проявляется финансово-экономический кризис, охвативший весь мир, последствия которого в большей степени имеют геополитический характер. Третьим является начало нового этапа отношений между США и Россией, получившего название «перезагрузка». Нельзя сказать, что кардинально изменились тренды во внешней политике, но поменялся характер методов, американцы стали вести дела в международных отношениях «мягче». Так в 2010 г. инициируются революции в арабских странах (объявленных Вашингтоном «осью зла»), усиливается внимание к Азиатско-Тихоокеанскому региону.

В 2012 г. переизбраны президенты США и РФ: какой будет следующий шаг алгоритма покажет история. Однако геополитическими противниками атлантического блока остаются Китай и Россия. Америка устремила свой взор на азиатско-тихоокеанский регион: усиливается военный контингент, идет поиск новых военно-морских баз, заключаются военные, экономические и политические союзы со странами-оппонентами КНР. Другими словами началась негласная борьба за господство в Тихом океане, США вновь пытаются вести политику «сдерживания».

По нашему мнению, на западном фронте Евразии США будут стремиться реализовать следующие проекты: 1) разрушение геополитического треугольника Россия-Китай-Иран; 2) привлечение РФ в качестве своего союз- 
ника против Китая; 3) применение арабской карты для дальнейшего выхода на Кавказ, в Центральную Азию - Сибирь. Наиболее интересным представляется третий вариант, потому что он отражает максиму $\mathrm{X}$. Маккиндера. Если у английского географа в качестве плацдарма влияния на хартленд в условиях советской империи выступала Восточная Европа, то почему в Российской Федерации в этом качестве не может выступить Кавказ и Центральная Азия?

Итак, рассмотренная нами концепция «хартленда» на макроуровне представляет собой в сущности планетарную модель расположения глобальных сил в которых стратегическое ядерное оружие является знаком вынесенным за скобки, т.к. при его достаточном наличии концепция «хартленда» существенно трансформируется В силу того, что с течением времени изменялись критерии, позволяющие выделить «сердце» Земли, менялись и его контуры, которые теперь совпадают, как принято считать, с границами Российской Федерации. Принцип работы внешнеполитических доктрин США в геополитическом пространстве представляет собой вполне четкий алгоритм. Он был реализован по трем направлениям: глобальный охват Евразии, региональное развитие сепаратизма в странах, подконтрольных
Москве и ставка на победу «марионеточных» элит дружественно настроенных к США. Для контроля над хартлендом США необходимо было последовательно подчинять своему влиянию от далеких пространств к прилегающим границам хартленда: Западная Европа - Восточная Европа - республики Советского Союза, а последовательное разоружение противника служило идеальным подспорьем в реализации геополитического замысла. Для того, чтобы оппонировать однополярным инициативам США в области обеспечения глобальной безопасности России необходимо организовать «зону своего приоритетного влияния, включая политическую, мировоззренческую, социальную, культурную, языковую и экономическую модель - Pax Russica», по аналогии c Pax America и возможными Pax China, Pax Indiana, Pax Latino-America и т. д. ${ }^{1}$ Границы между ними пройдут не по линии ныне существующих государственных рубежей, но по иным, более гибким и менее формализованным признакам (язык, этнос, культура, хозяйственная модель, религия и т. д.) ${ }^{2}$. Здесь необходима выработка комплексных и в чем-то асимметричных ответов, так как подобные сценарии так же хорошо изучены в США благодаря трудам С. Хантингтона и его последователей.

4. Дугин А. Г. Глобальная безопасность. http://konservatizm.org/konservatizm/ theory/230210142701.xhtml

5. Официальный сайт Центра по изучению проблем разоружения, энергетики и экологии МФТИ http;//www.

\footnotetext{
1 Дугин А.Г. Проект Евразия. http://www.evrazia.org/ modules.php?name $=$ News\&file $=$ article $\&$ sid $=1839$ 2 Дугин А. Г. Глобальная безопасность. http://konservatizm.org/konservatizm/theory/230210142701.xhtml
} 
armscontrol.ru/start/rus/

6. Хиллари Клинтон: Мы не дадим России объединиться с соседями 07.12.2012. http://www.pravda.ru/news/world/07-122012/1137689-hillari_doesnt_like_it-0/

7. A geostrategy for Eurasia. // Foreign Affairs / September/October 1997, p. 50-64

8. Captive national week // Bush G.W. / сайт: архива Белого Дома. http:// georgewbush-whitehouse.archives.gov/ news/releases/2008/07/20080718-3.html

\section{References (transliterated)}

1. Ageev A. I. Kurdyumov V. S., Malinetsski i G. G. Proektirovanie budushchego. Krizis i idei S. P. Kurdyumova // Ekonomicheskie strategii. 2009. № 4.

2. Golos Ameriki. Sreda, 22 Fevral' 2012. http://voanews.com/russian/grigoryev/tag/ olbrait/
3. Dugin A. G. Proekt Evraziya. http://www. evrazia.org/modules.php?name $=$ News\&fil $\mathrm{e}=\operatorname{article} \& \operatorname{sid}=1839$

4. Dugin A. G. Global'naya bezopasnost'. http://konservatizm.org/konservatizm/ theory/230210142701.xhtml

5. Ofitsial'nyi sait Tsentra po izucheniyu problem razoruzheniya, energetiki i ekologii MFTI http;//www.armscontrol.ru/ start/rus/

6. Khillari Klinton: My ne dadim Rossii ob"edinit'sya s sosedyami 07.12.2012. http://www.pravda.ru/news/world/07-122012/1137689-hillari_doesnt_like_it-0/

7. A geostrategy for Eurasia. // Foreign Affairs / September/October 1997, p. 50-64

8. Captive national week // Bush G. W. / sait: arkhiva Belogo Doma. http:// georgewbush-whitehouse.archives.gov/ news/releases/2008/07/20080718-3.html 